Sofia Xavier, Joana Magalhães, Bruno Rosa, José Cotter

Hemospray use in upper gastrointestinal bleeding from tumor: Is it the answer?

We read with great interest the article entitled "The efficacy of Hemospray in patients with upper gastrointestinal bleeding from tumor" by Pittayanon et al [1]. The authors enrolled 24 patients with upper gastrointestinal bleeding originating from a primary or metastatic upper gastrointestinal tract tumor and compared several outcomes (14-day rebleeding rates, length of hospital stay and mortality rate at 30-day follow up) between the group treated with Hemospray as the first-line hemostatic therapy $(n=14)$ and a control group treated with conventional endoscopic hemostatic methods (coaptation therapy, argon plasma coagulation, and mechanical hemostasis). The authors found that the 14-day rebleeding rate and the 30-day mortality rate in the Hemospray group was 3 times lower than in the control group, even though statistical significance was not reached (10\% vs. $30 \% ; P=0.60$ and $10 \%$ vs. $30 \%, P=0.7$, respectively).This is a relevant topic since hemostatic efficacy in bleeding originating from tumoral lesions is far from ideal and rebleeding rates are significant $[2,3]$, which proves that new therapeutic approaches are needed in this set of patients.

We would like to report a case in which Hemospray played a critical role in the hemostasis of a bleeding tumor lesion. An 80 -year-old male was admitted in the emergency room with complaints of asthenia, pallor and melena with 72 hours of evolution. At admission the patient was hemodynamically stable and blood workup showed anemia with hemoglobin of $8.1 \mathrm{~g} / \mathrm{dL}$. Upper gastrointestinal endoscopy was performed within the first 12 hours and showed a $30-\mathrm{mm}$ Forrest IIa ulcer located in the pre-pyloric posterior wall and lesser curvature ( $\bullet$ Fig. 1), which was treated with epinephrine (10 cc, $1: 10.000)$ and bipolar eletrocoagulation (20W) with hemostatic efficacy. After endoscopy, the patient was admitted to an intermediate care unit under standard

\section{License terms}

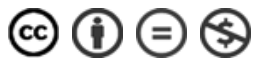

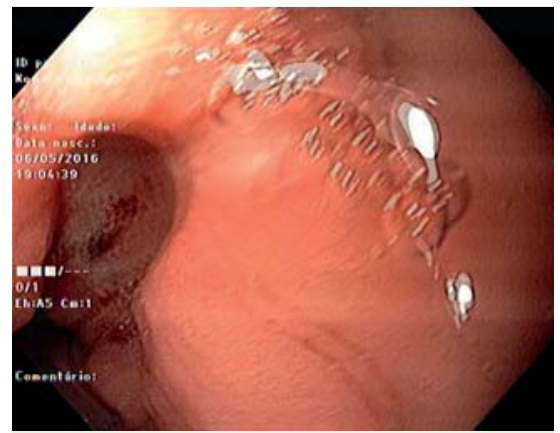

Fig. 1 Forrest lla ulcer.

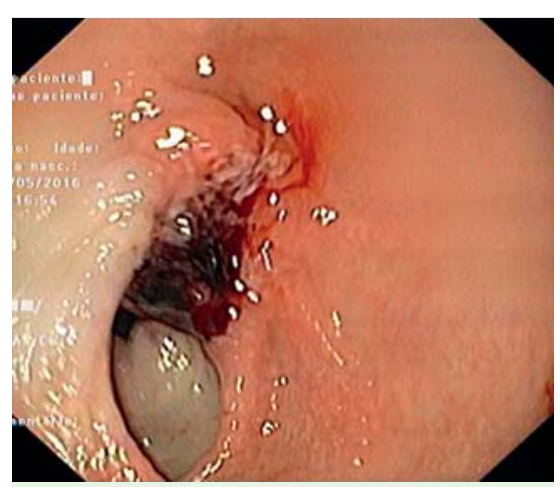

Fig. 2 Ulcer underneath clot.

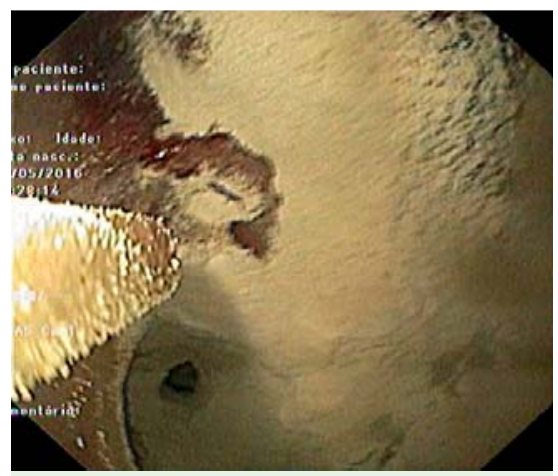

Fig.3 Lesion treated with Hemospray.

post-endoscopic care with a 72-hour proton pump inhibitor infusion.

Four days after admission, the patient had a new drop in hemoglobin levels (from $9.1 \mathrm{~g} / \mathrm{dL}$ to $7.3 \mathrm{~g} / \mathrm{dL}$ ) with melena recurrence. Repeat upper gastrointestinal endoscopy was performed and showed a large clot in the pre-pyloric posterior wall, partially detachable with vigorous irrigation, underneath which was visible the previously reported ulcer, with great friability and conditioning anatomical distortion, this time treated with 1 cartridge of Hemospray with hemostatic efficacy (๑ Fig. 2 and $\bullet$ Fig. 3).

The patient remained stable with sustained increase in hemoglobin and with- out further need for emergency endoscopic intervention or red blood cell transfusion. He was later endoscopically reevaluated with visualization of a clean base ulcer (Forrest III) which was biopsied and diagnosed as an adenocarcinoma.

This case exemplifies the difficulty in the clinical and endoscopic approach to tumor bleeding lesions. Upper gastrointestinal tumors account for $2 \%$ to $4 \%$ of nonvariceal upper gastrointestinal bleeding episodes [4]. These lesions are amenable to conventional endoscopic hemostatic therapy, with reported success rates ranging from $67 \%$ to $100 \%[5,6]$. However, recurrence rates are significant with a current review reporting rebleeding rates ranging from $41 \%$ to $80 \%$ [7]. These results are far from ideal and create a demand for a more efficient therapeutic solution.

In our case, the patient was treated primarily with combined therapy using epinephrine injection with contact thermal therapy, in concordance with current guidelines [4] and Hemospray was reserved for treatment of recurrence. However, considering the superior hemostatic efficacy of Hemospray as first-line therapy in bleeding tumor lesions shown by the article authors, and taking into account the favorable result obtained in our case, we believe that Hemospray may play a role as first-line treatment in selected forms of upper gastrointestinal bleeding, namely those arising from tumors. This may temporize bleeding and allow patients to remain stable, with less need for invasive procedures, until a more definitive therapeutic solution, such as surgery or radiotherapy, can be performed.

\section{Competing interests: None}

\section{References}

1 Pittayanon R, Prueksapanich P, Rerknimitr $R$ The efficacy of Hemospray in patients with upper gastrointestinal bleeding from tumor. Endoscopy international open 2016; 4: E933-E936

2 Heller SJ, Tokar JL, Nguyen MT et al. Management of bleeding GI tumors. Gastrointestinal endoscopy 2010; 72: 817-824

3 Conway JD, Adler DG. Asge Technology C. et al. Endoscopic hemostatic devices. Gastrointestinal endoscopy 2009; 69: 987-996

4 Gralnek IM, Dumonceau JM, Kuipers EJ et al. Diagnosis and management of nonvariceal upper gastrointestinal hemorrhage: European Society of Gastrointestinal Endoscopy (ESGE) Guideline. Endoscopy 2015; 47: a1 a46

5 Kim YI, Choi IJ, Cho SJ et al. Outcome of endoscopic therapy for cancer bleeding in patients with unresectable gastric cancer. 
Journal of gastroenterology and hepatology 2013; 28: 1489-1495

6 Savides TJJD, Cohen J, Randall GM et al. Severe upper gastrointestinal tumor bleeding: endoscopic findings, treatment, and outcome. Endoscopy 1996; 28: 244-248
7 Elmunzer BJ, Young SD, Inadomi JM et al. Systematic review of the predictors of recurrent hemorrhage after endoscopic hemostatic therapy for bleeding peptic ulcers. The American journal of gastroenterology 2008; 103: 2625-2632 ; quiz 2633

\section{Sofia Xavier}

Hospital Senhora da Oliveira

Gastroenterology dos Cutileiros

Creixomil Guimarães

Guimarães 4835-044

Portugal

Phone: +351-253-540330

Fax: +253513592

smaxavier@gmail.com 